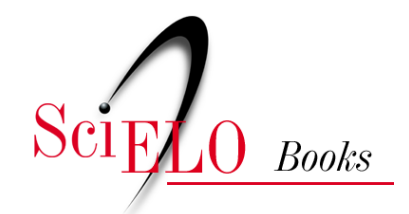

\title{
EDUFU
}

\section{Jogo teatral e criação literária}

\author{
Vilma Campos dos Santos Leite
}

\section{SciELO Books / SciELO Livros / SciELO Libros}

LEITE, V.C.S. Jogo teatral e criação literária. In: FLORENTINO, A., and TELLES, N., eds.

Cartografias do ensino do teatro [online]. Uberlândia: EDUFU, 2008, pp. 299-307. ISBN 978-857078-518-3. https://doi.org/10.7476/9788570785183.0029.

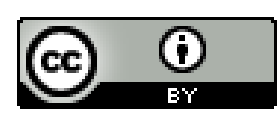

All the contents of this work, except where otherwise noted, is licensed under a Creative Commons Attribution 4.0 International license.

Todo o conteúdo deste trabalho, exceto quando houver ressalva, é publicado sob a licença Creative Commons Atribição $\underline{4.0}$.

Todo el contenido de esta obra, excepto donde se indique lo contrario, está bajo licencia de la licencia $\underline{\text { Creative Commons }}$ Reconocimento 4.0. 


\section{JOGO TEATRAL E CRIAÇÃO LITERÁRIA}

Vilma Campos dos Santos Leite

O sistema dos jogos teatrais de Viola Spolin (1906-1994) está entre as abordagens de aprendizagem teatral que trabalha com a noção de que todos são capazes de atuar e pressupõe que a habilidade de comunicação cênica pode ser aprendida, em contraposição à noção de talento inato.

Tal estrutura, ao propor uma ruptura com a noção de dom, é pertinente para a inclusão da escrita literária enquanto habilidade que também pode ser desenvolvida. Ao incluir o papel do jogador-escritor, ponho em foco as intersecções e similaridades entre a esfera criativa do escrever e do fazer teatral.

Originalmente nos jogos teatrais, os participantes são revezados em dois papéis: "jogadores do palco" e da "platéia". Todos passam por eles sucessivamente, mas não simultaneamente, ou seja, enquanto os jogadores do palco estão preocupados em resolverem determinado problema cênico ou "foco", os jogadores da platéia, durante o jogo, estão atentos ao mesmo para a "avaliação" posterior.

É a partir das observações da platéia, da interação entre ela e os jogadores do palco, bem como do revezamento entre os dois papéis, que a aprendizagem teatral acontece.

Em A criação literária e o jogo teatral ${ }^{1}$, acrescento ao sistema de Spolin a figura do jogador-escritor como terceiro papel. O conceito de dialogismo do pensador russo Bakhtin (1895-1975) fundamenta o trabalho enquanto interação entre os sujeitos e os textos, considerando o ponto de vista do outro para uma construção própria.

Como para os “jogadores do palco" e "da platéia”, há uma troca sucessiva, só que neste caso, enquanto alguns jogam na área de jogo e outros na platéia avaliam, uma ou mais pessoas trabalham com a imagem do jogo como sugestão de escrita. Em um outro jogo ou sessão de trabalho, aquele que escreveu se torna jogador da platéia e palco, enquanto que um outro que assumira estes dois papéis experimenta a escrita.

O papel do jogador-escritor é estimulado a partir da disponibilidade inicial de um ou mais jogadores em experimentar esta nova posição do jogo. O texto ou textos produzidos, a avaliação e o tornar o texto escrito objeto de novos jogos impulsionam outros jogadores a escrever.

${ }^{1}$ LEITE, Vilma Campos dos Santos. A criação literária e o jogo teatral. 2003. Dissertação (Mestrado) - Escola de Comunicações e Artes, Universidade de São Paulo, São Paulo, 2003. 
Destaco o protocolo como procedimento fundamental durante todas as fases do processo. O protocolo é o instaurador do exercício da escrita. A materialização dele como ato criativo e como instrumento dialógico numa prática simultânea revela-nos possibilidades iniciais de gêneros de texto em determinado grupo e a transformação desses textos no decorrer das sessões.

Podemos estabelecer pelo menos três fases de trabalho nesse processo: jogos e protocolos com ponto de partida, textos de autores alheios ao grupo e a introdução do terceiro papel, o do jogador-escritor, ao jogo teatral.

\section{Jogos teatrais e protocolos como ponto de partida}

O protocolo é um procedimento que Brecht já incorporara ao jogo como instrumento de avaliação estética. A prática desse instrumento como propósito da aprendizagem teatral tem se mostrado também como um exercício de apropriação do ato da escrita. Cada jogador tem possibilidades de partir de gêneros que lhe são mais convenientes na escrita, sem se afastar da avaliação na linguagem teatral.

Como nos informa Koudela ${ }^{2}$ durante a fase de experimentação dos Versuche, Brecht protocolava as reações dos participantes com preocupação científica de compará-las e como subsídios de avaliação, porque ele concebia as peças didáticas como ponto de partida ou como experimentos escritos em elos de uma mesma cadeia.

Tenho procurado utilizar o protocolo como avaliação estética dos jogos e textos em jogo, bem como oportunizar o ato como exercício de escrita criativa. Todos os jogadores avaliam cada sessão de trabalho. Relatando ou ficcionando. Em prosa ou verso. Ao focar cada protocolo, coloco a materialidade de cada texto escrito para dialogar e interagir.

Se inicialmente os jogadores não querem escrever, eles desenham ou produzem imagens gráficas. $O$ intuito nessa fase é deixar cada membro o mais "livre" possível para uma criação pessoal. A diferença é acolhida e bem-vinda.

É fundamental fomentar o exercício constante, independente de aparecer mais ligado a uma descrição contextual, ou de ser trabalhado esteticamente.

Emissão oral, recepção auditiva e até a troca de textos escritos têm sido ações que garantem o não encaminhamento para um diário íntimo, principalmente porque é necessário incentivar a interação e o diálogo entre os participantes.

Enquanto orientadora de uma sessão de trabalho, tenho me deparado com a prática de incentivar o jogador a dizer ou mostrar o seu texto, encorajando a socialização. Mas, por outro lado, cada enunciador do protocolo pode optar por uma enunciação oral e feita por ele, selecionando os trechos que quer comunicar ao grupo. É uma condução que preza o papel ativo de cada membro.

No decorrer do processo, quando os participantes ficam mais seguros de sua enunciação pessoal, socializam os protocolos também por escrito. A cooperação vai se fazendo presente. Escrever e dizer protocolos passa também a fazer parte do jogo, embora num momento distinto e não simultâneo com o jogo teatral.

${ }^{2}$ KOUDELA, Ingrid Dormien. Brecht: um jogo de aprendizagem. São Paulo: Edusp: Perspectiva, $1991.176 \mathrm{p}$. 
Para cada um dos jogadores é um dos aspectos de cada sessão que chama a atenção. Cria-se uma expectativa quando alguém vai dizer o seu protocolo porque há um diálogo entre eles. Esse olhar do "outro" alimenta o "eu” de cada jogador:

Ao olhar para trás do caminho, percebo o quanto me confundi, me embaracei nas linhas dos textos escritos no início da caminhada. Havia uma preocupação em escrever. Só. Mais nada. Acho que todos assim pensavam. Depois, gradativamente, isso foi se tornando necessário, imprescindível. As experiências, vivências e sensações precisavam ser registradas; na memória se perderiam. Os textos fluíam, dançavam, se soltavam com uma maior 'facilidade'. A preocupação não era mais escrever [...], mas como escrever [...], como expressar tantas emoções [...]. Como, na tela, saber as cores que se vai usar. Chegar para trás, olhar a tela, comparar, fechar um pouquinho os olhos para perceber as nuanças, formas, linhas, a composição! A escrita agora era uma pintura. Cuidadosamente pensada, analisada e reescrita (jogador 12 - auto-avaliação em 23 de abril de 2002).

No relato anterior, é perceptível a trajetória do jogador. A natureza estética ganhou importância. A diversidade de protocolos e os diálogos provocados configuram-se em parâmetros dentro do próprio grupo, preparando o objetivo final, que é a criação de textos de natureza literária a partir dos próprios jogos.

\section{Apropriação lúdica de textos}

Escrever ainda aqui é um hábito que vai sendo exercitado no processo de avaliação estética da linguagem teatral (protocolo), mas que vai também se alimentando pelos textos de autores alheios ao grupo, que passam a ser objeto de jogo. Estes textos podem ser de natureza diversa: em prosa ou verso, em diálogos ou não.

Os jogadores são levados a familiarizar-se com procedimentos de sensibilização do texto em jogo. Para tal apropriação, utilizo os procedimentos de $\mathrm{Pupo}^{3}$ : todos caminham e lêem ao mesmo tempo; um pára, todos param de caminhar e de ler; um caminha, todos continuam a ler e caminhar; caminhar e a um sinal enunciar para alguém: próximo ou distante; ler para jogadores com olhos fechados etc.

Outros procedimentos de leitura e experimentação com o texto das práticas da Prof ${ }^{a}$. Dra. Maria Lúcia de Barros Pupo e da Prof ${ }^{a}$. Dra. Ingrid Dormien Koudela ${ }^{4}$ são exemplares, entre eles: todos os jogadores numa roda virada para fora, cada um escolhe uma passagem do texto e a retoma não simultaneamente, mas sucessivamente, em diferentes entonações.

A instrução nesse ou em outros procedimentos é a emissão "ao outro". A enunciação para alguém. Na escuta ou no olhar. Cada enunciação como reação à ação anterior, provocando o diálogo e auxiliando os participantes a saírem do "eu" enquanto grupo e irem a um "outro" mais distante, presente na materialidade da leitura do texto.

3 PUPO, Maria Lúcia de Souza Barros. Palavras em jogo. Textos literários e teatro educação. 1997. 160 p. Tese (Livre-Docência) - Escola de Comunicações e Artes, Universidade de São Paulo, São Paulo, 1997.

${ }^{4}$ Professoras e pesquisadoras da linha Teatro e Educação da Escola de Comunicações e Artes da Universidade de São Paulo - ECA-SP. 
A opção por trabalhar em um determinado momento do processo com textos que podem ser também de autores consagrados é um elemento a mais para alimentar o papel do jogador-escritor que será introduzido na terceira fase do trabalho.

Quando os textos de autores diversos passam a ser objeto de jogo, percebe-se uma transformação na silhueta dos protocolos. A escrita vem acrescida dos elementos lúdicos vivenciados na área do jogo. Há jogadores que arriscam protocolos em versos ou outros elementos literários da prosa que não se manifestavam quando estava em foco o jogo sem estímulos de fragmentos ou textos escritos. As aliterações, rimas, enunciação de nomes próprios que não correspondem aos verdadeiros dos jogadores, clamando por personagens passam a ser recorrentes. É uma transposição para o universo ficcional. Os protocolos manifestam imagens, analogias e metáforas, anunciando o momento de introduzir o terceiro papel ao jogo: o do jogador-escritor.

\section{O papel do jogador-escritor}

Finalmente, jogadores da platéia são convidados a fazer algo distinto da avaliação do jogo. O foco dos voluntários é registrar imagens por escrito, enquanto um determinado jogo teatral acontece ou logo após a sua ocorrência, ao mesmo passo que os jogadores da platéia o avaliam do ponto de vista da linguagem cênica.

A instrução dada aos participantes é: não escreva um texto inteiro, pronto, acabado. Parta de uma imagem, metáfora ou analogia que você faça com o presente desse jogo. Não ofereça uma reprodução do real. Não de um o quê, onde ou personagem real que envolve os jogadores do palco, mas das sensações ou imagens que tal foco em jogo provoca em você.

Os jogadores utilizam o jogo como uma imagem geradora no sentido que lhe dá Salles enquanto processo de criação artística: "As imagens geradoras que fazem parte do percurso criador funcionam, na verdade, como sensações alimentadoras da trajetória, pois são responsáveis pela manutenção do andamento do processo e, conseqüentemente, pelo crescimento da obra"5.

Essas imagens são trabalhadas pelo jogador-escritor até a sessão seguinte (dois dias, duas semanas, enfim, de acordo com a periodicidade de encontro do grupo). De posse do texto escrito, este é copiado para todos os jogadores, a fim de que a enunciação não fique apenas no nível da oralidade e para que se possa experimentar o texto em um novo jogo, similarmente aos textos de autores alheios que são trabalhados na fase anterior.

Para exemplificar o percurso do jogador-escritor no terceiro papel, reproduzo e analiso a seguir o texto Inquietação, escrito a partir da imagem "carrossel" de um parque de diversões, no jogo Um objeto move os jogadores ${ }^{6}$.

\footnotetext{
${ }^{5}$ SALLES, Cecília Almeida. Gesto inacabado. Processo de criação artística. São Paulo: Anna Blume, 1998. p. 57.

${ }^{6}$ SPOLIN, Viola. Improvisação para o teatro. São Paulo: Perspectiva, 1987. p.64; SPOLIN, Viola. Jogos teatrais. O fichário de Viola Spolin. São Paulo: Perspectiva, 2001. p. A46.
} 
Sabrina, inquieta com tanto calor, levanta do sofá e vai até o seu armário, revira as gavetas sem sucesso. Corre para o quarto do irmão e também revira suas gavetas, mas não acha o que procura. Vai até o banheiro e o acha pendurado e molhado. Não se importa, afinal está quente e ela quer se refrescar. Então veste seu lindo e ensopado biquíni verde, corre até o playground e mergulha com satisfação na minúscula piscina de plástico (jogador-escritor - 19/03).

É importante informar que a personagem Sabrina (que não corresponde a nenhum nome de jogador da turma) já vinha se fazendo presente enquanto nome nos últimos protocolos da jogadora-escritora em questão, mas lá evidenciando avaliações estéticas de elementos reais da sessão de trabalho.

Os jogadores da turma trabalharam na sessão posterior com o texto Inquietação nas mãos, de acordo com os procedimentos de apropriação sensível do texto como os apontados em $\mathrm{Pupo}^{7}$, já utilizados em textos de autores terceiros.

Nesse exemplo, como em outros, o protocolo continua realizando a sua função de avaliação estética da linguagem teatral e também contribui para o desenvolvimento sensorial e poético, estabelecendo diálogo entre o texto Inquietação e os jogos. Evidenciam diálogo de relações e sensações entre o jogo e o texto:

Com o corpo, 3 Sabrinas a representar

Euforia, inquietação, sensação de bem-estar

Levanta, corre, revira a procurar

Em um espaço livre a brincar.

(jogador 11- protocolo 14 de 26 de março)

Ah! É você inquietação?

Que avança como um furacão

Que vem em minha direção

Que abala minha emoção

Que explode meu coração

De tanta perturbação.

(jogador 13 - protocolo 14 de 26 de março)

Sabrina? ou Sabrinas? Os lugares? Onde? Inquietações? Ações? Quem? Surgiu a irmã de Sabrina? A piscina? E o sofá que voa? Quanta coisa um texto trás... E agora que a autora viu o seu texto dramatizado, ela vai reescrever a nossa Sabrina.

(jogador 3 - protocolo 14 de 26 de março)

Os protocolos dialogam inclusive com o poema de Cecília Meireles, que fora trabalhado por esse grupo, quando enunciam a movimentação física: "Levanta, corre, revira a procurar/em um espaço livre a brincar”. Os objetos também tomam os movimentos emprestados: "E o sofá que voa”.

7 PUPO, 1997. 
O “eu” vai tão em direção ao "outro" (“O coração explode”), tanto quanto o "outro" invade o "eu”: "Ah! É você inquietação? Que avança como um furacão, Que vem em minha direção”.

Sabrina não é mais criação única de um jogador. Ela se materializa, se fisicaliza e se transforma na "nossa Sabrina". O dialogismo, ou a interação entre os jogos e textos, permite que outros jogadores apropriem-se de Sabrina.

Os pontos de vista evidenciados ou compartilhados por esse dialogismo fazem com que o jogador-escritor reescreva seu texto:

Uma típica tarde de um domingo de verão; a alta umidade do ar, o suor a escorrer sobre a pele já úmida, a roupa grudada no corpo...

O calor é tanto que até o sofá parece ter calor próprio.

Sabrina, que ali está deitada, revira-se tentando achar uma posição mais confortável, mas o contato direto da pele com o sofá plastificado produz pequenas piscinas de suor que se espalham entre ele e ela.

Então levanta-se, vai em direção à sacada e abre a porta de vidro que dá para o playground.

Uma brisa suave entra pela porta, passeia pela sala e envolve Sabrina em uma deliciosa sensação de frescor e liberdade, conduzindo-a para fora.

Recostando-se no parapeito, volita entre brisas e ruídos infantis, procurando em gavetas antigas algo que faltava ou talvez que não chegara a ter.

Vozes, gritos, risadas e choros sempre se calavam com água, fosse de uma lágrima ou de um mergulho, de saliva ou de mercúrio.

A brisa agora ecoa dentro de gavetas vazias, passando de uma a outra, silenciosa, confusa e perdida.

De repente: um ruído, e um chamado a traz de volta, e Sabrina finalmente percebe que o que procurava estava todo tempo ali. Com um lindo sorriso no rosto, um biquíni fofo a combinar com seus olhinhos de esmeralda, molhadinha a pingar toda a sala, ela entra e corre em direção a Sabrina.

Carinhosamente as duas se abraçam e, em meio à água e ao suor que ali se misturavam, o frescor e o calor se fundem em um único e verdadeiro sentimento (jogador-escritor 2 - segunda versão de Inquietação).

O encontro acontece não só na narrativa ("carinhosamente as duas se abraçam. [...] se fundem em um único e verdadeiro sentimento”), mas também enquanto realidade de trabalho. $O$ jogador-escritor teve percepção para interagir com os elementos surgidos nos jogos teatrais, retrabalhando-os no texto. Os jogadores do palco e da platéia também continuam a interagir, por meio dos protocolos, com o texto do jogador-escritor: "Sabrina ficou mais legal onde estava mais viva a presença da irmã. O texto era mais detalhista. Foi um texto um pouco diferente, mas ainda era a Sabrina." (jogador 4 - protocolo 16 em 9 de abril).

A Sabrina não é mais "o eu” ou "o outro", ela é "o nosso", mas não como uma massa indistinta. Importa menos a autoria, importa mais a contribuição pessoal e única de cada jogador.

O dialogismo aconteceu na situação de jogo e também com a situação de escrita e reescrita, sobretudo porque o jogador-escritor pôde ouvir diferentes versões 
sobre a sua criação, sensibilizada pelo exercício do jogo e do protocolo. O protocolo ampliou o repertório dos jogadores, avançou a produção escrita.

No jogo, a interação entre os sujeitos leva à aprendizagem da linguagem teatral porque contribui para a solução do problema ou foco. No presente processo, o protocolo foi ponto de partida para a interação entre os textos e tornou-se objeto de aprendizagem escrita, na medida em que incentivou o exercício simultâneo e sistemático com a criação literária.

Os jogadores puderam sentir-se mais capazes e interessados em escrever. Detalhamentos sensoriais dos jogos também aconteceram na escrita. Elementos poéticos e narrativos foram se fortalecendo nessa troca de protocolos.

Podemos ter jogadores na platéia cuja função é escrever a partir de uma imagem, metáfora ou analogia do jogo. O texto Inquietação, por exemplo, surgiu da imagem de jogo. O texto não simplesmente sublinha, descreve ou relata o jogo. Ele é uma imagem ou uma analogia que a jogadora fez. Esse processo foi “aquecido" e "preparado" com o protocolo constante em todas as sessões de trabalho.

Quando o texto criado pelo jogador-escritor volta para o jogo, os jogadores descobrem novos elementos ao brincar e trabalhar com o texto. Percebem que o texto de um colega é tão rico de possibilidades quanto o texto de um autor consagrado. Pontos de vista são visíveis no jogo. Esses pontos de vista diversos levam o jogador-escritor a reescrever o texto, numa manutenção do dialogismo entre os textos e entre os próprios interlocutores.

A segunda versão de Inquietação é mais detalhada e aprofundada do que a primeira porque pôde dialogar com os jogos e com outros textos. Os elementos sensoriais, por exemplo, tornam-se mais intensos, assim como deve acontecer num jogo teatral. A personagem do texto não se levanta do sofá aleatoriamente, são os efeitos da alta temperatura descritos de maneira minuciosa que a levam a agir. A autora desta versão nos leva a enxergar, ouvir, cheirar, pegar e sentir o gosto.

Destaco, também desta segunda versão, elementos simbólicos que foram trabalhados pela autora a partir das imagens de jogo. O elemento líquido é reiterado seja pela água da piscina, seja pelo calor que quase dissolve os elementos sólidos, como o sofá. Outro elemento simbólico é o biquíni. Sabrina o procura, mas talvez nem "chegara a ter" o traje. A busca é pelo que o objeto biquíni representa.

Real e imaginário misturam-se em Sabrina e essa ambigüidade é outro elemento interessante que o jogador-escritor consegue alcançar. Sabrina abraça a imagem do passado, ela mesma ou a irmã?

Esses resultados não teriam sido possíveis se não tivessem o protocolo como ponto de partida. Ele foi importante recurso de interação, uma que por meio dele transformações textuais aconteceram, como, por exemplo, a utilização do texto poético e depois a utilização do personagem de ficção. O protocolo revelou que o instrumento instaurado por Brecht para o jogo em muito se ajusta à concepção dialógica. "Ao almejar como função mais nobre dar conta do caráter estético do experimento com modelo de ação (imagem e/ ou texto), o protocolo promove a dialética como método de pensamento"8.

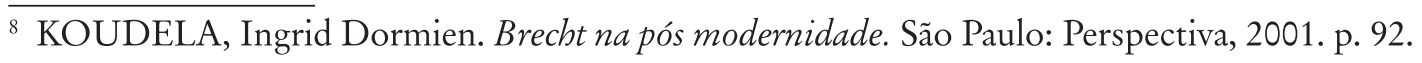




\section{REFERÊNCIAS}

BAJARD, Elie. Ler e dizer. São Paulo: Cortez, 1994.

BAKHTIN, Mikhail. Estética da criação verbal. 3. ed. São Paulo: M. Fontes, 2000.

BAKHTIN, Mikhail. Marxismo e filosofia da linguagem. 4. ed. São Paulo: Hucitec, 1988.

BAKHTIN, Mikhail. Questões de literatura e de estética. A teoria do romance. 3. ed. São Paulo: Hucitec, 1993.

BARROS, Diana Luz Pessoa de; FIORIM, José Luiz (Org.). Dialogismo, polifonia, intertextualidade em torno de Bakbtin. São Paulo: Edusp, 1994.

BAUNE, Jean; GROSJEAN, Bernard. Petites formes... grands enjeux. Cahiers Pédagogiques, Paris, n. 337, p 47-49, oct. 1995.

BRAIT, Beth (Org). Bakbtin, dialogismo e construção do sentido. São Paulo: Unicamp, 1997.

BRECHT, Bertolt. Diário de Brecht. Porto Alegre: L\&PM, 1995.

CALKINS, Lucy McCormick. A arte de ensinar a escrever. O desenvolvimento do discurso escrito. Porto Alegre: Artmed, 1989.

DOLZ, Joaquim; SCHNEUWLY, Bernard. Gêneros e progressão em expressão oral e escrita. Elementos para reflexões sobre uma experiência suíça (francófona). Tradução de Roxane $\mathrm{H}$. R. Rojo. [S.l.]: Enjeux, [19--?]. p. 31, 49. Mimeografado.

GAMA, Joaquim Cesar Moreira. Produto teatral: a velha-nova história. Experimento com alunos do Ensino Médio. 2000. 262 p. Dissertação (Mestrado em Artes) - Escola de Comunicação e Artes, Universidade de São Paulo, São Paulo, 2000.

KOUDELA, Ingrid Dormien. Brecht: um jogo de aprendizagem. São Paulo: Edusp: Perspectiva, 1991.

KOUDELA, Ingrid Dormien. Brecht na pós modernidade. São Paulo: Perspectiva, 2001.

KOUDELA, Ingrid Dormien. Texto e jogo. São Paulo: Fapesp: Perspectiva, 1996.

KOUDELA, Ingrid Dormien. Um vôo brechtiano. Teoria e prática da peça didática. São Paulo: Fapesp: Perspectiva, 1992.

OLIVEIRA, Ulisses Ferraz de Oliveira. Veredas do estranhamento. Pedagogia do teatro e produção de texto. 2001. 265 p. Tese (Doutorado em Educação da Faculdade de Educação) - Universidade de São Paulo, São Paulo, 2001. 
PAIS, Marco Aurélio Vieira. A aquisição da competência semiótica para a atuação Teatral. 2000. 190 p. Dissertação (Mestrado em Artes Cênicas) - Escola de Comunicações e Artes, Universidade de São Paulo, São Paulo, 2000.

PAVIS, Patrice. Dicionário de teatro. São Paulo: Perspectiva, 1997.

PUPO, Maria Lúcia de Souza Barros. Palavras em jogo. Textos literários e teatro educação. 1997. 160 p. Tese (Livre-Docência) - Escola de Comunicações e Artes, Universidade de São Paulo, São Paulo, 1997.

SALLES, Cecília Almeida. Gesto inacabado. Processo de criação artística. São Paulo: Anna Blume, 1998.

SPOLIN, Viola. Improvisação para o teatro. São Paulo: Perspectiva, 1987.

SPOLIN, Viola. O jogo teatral no livro do diretor. São Paulo: Perspectiva, 1999.

SPOLIN, Viola. Jogos teatrais. O fichário de Viola Spolin. São Paulo: Perspectiva, 2001. 